12th LUMEN International Scientific Conference Rethinking Social Action. Core Values in Practice | RSACVP 2019 | 15-17 May 2019 | lasi - Romania

\title{
The Effects of Circuit Training on Muscle Strength and Resistance
}

\author{
Cristina-Elena MORARU, Alexandru-Rareş PUNI, \\ Ioan-Răzvan BELDIMAN
}

https://doi.org/10.18662/lumproc. 166

How to cite: Moraru, C.-E., Puni, A.-R., Beldiman, I.-R. (2019). The Effects of Circuit Training on Muscle Strength and Resistance. In C. Ignatescu (ed.), 12th LUMEN International Scientific Conference Rethinking Social Action. Core Values in Practice, 15-17 May 2019, Iasi - Romania (pp. 208-216). Iasi, Romania: LUMEN Proceedings. https://doi.org/10.18662/lumproc.166 


\title{
The Effects of Circuit Training on Muscle Strength and Resistance
}

\section{Cristina-Elena MORARU1*, Alexandru-Rareş PUNI², Ioan-Răzvan BELDIMAN ${ }^{3}$}

\begin{abstract}
The circuit is a methodical procedure with highly efficient effects in the development of motor qualities, mainly strength and resistance. The purpose of this paper was to demonstrate the efficiency of training in the circuit in the development of this motor quality. The sample within the research comprised 30 women aged 25-35 and who practiced 3 practices per week for 6 months. The independent variable included circuits for beginners (30" workout - 30" pause), circuits for middle level (45" workout - 30" pause) and circuits for advanced (50" workout - 30" pause). The tests applied concerned the strength and resistance of abdominal muscles, of the back, of the legs and of the arms. Findings. In the test for the strength and resistance of abdominal muscles, the values of the average and of standard deviation were $13.8 \pm 1.52$ initially and $15.2 \pm 1.08$ finally; concerning the strength and resistance of the back muscles, the values increased from 21.46 \pm 1.684 initially to $23.53 \pm 1.641$ finally; in the strength and muscles of the legs, the values ranged between $14.86 \pm 1.767$ initially and $16.80 \pm 1.473 ;$ in the strength and muscles of the arms, the values recorded an increase from $14.40 \pm 0.985$ initially to $16.26 \pm 0.961$ finally. The present research demonstrated that the use of circuit workout can improve the motor qualities of strength and it can also improve the motor qualities of strength and resistance, which confirms the purpose of the paper.
\end{abstract}

Keywords: Fitness; strength; circuit training.

\section{Introduction}

The phenomenon of physical exercises or generally defined as "fitness", "exercise", "conditioning", "resistance training" or even better "fitness training"; nonetheless, is an absolutely complex reality. Beyond

\footnotetext{
1 “Alexandru Ioan Cuza” University, Iaşi, Romania, gimcristinamoraru@yahoo.com

2 “Alexandru Ioan Cuza” University, Iaşi, Romania, punirares@yahoo.com

3 "Ştefan cel Mare” High School Codăeşti, Vaslui, Romania, rzv.beldiman@yahoo.com

* "Alexandru Ioan Cuza” University, Iaşi, Romania, gimcristinamoraru@yahoo.com 
doubt, using the term fitness, we can identify an array of activities conducted daily in fitness centers (Gyms) and "they may be regrouped into Gym resistance training activities; Group fitness activities; Functional fitness activities".

In the most recent decade, "the activities undergoing the term Fitness have evolved. In the beginning, aerobics, step aerobics, jogging, conditioning and bodybuilding represented the most common gym activities enabling the population to "be fit", nowadays we find more diversified and more careful activities for the necessities of active and non-active population activities. Some examples thereof are funky, zumba, fit box, cycling activities, besides calisthenics based training, cross fit, suspension training, kettlebell training, total body conditioning; furthermore, core training, boot camp, functional training, circuit training, pilates, yoga, stretching" [13].

In order to have substantial health benefits, "adults should perform at least 150 minutes (2 hours and 30 minutes) a week of moderate-intensity physical activity, or 75 minutes (one hour and 15 minutes) a week of vigorous-intensity aerobic physical activity, or a similar combination of moderate- and vigorous- intensity aerobic activity. Aerobic activity must be performed in episodes of at least 10 minutes each and preferably, it should be timed throughout the week" [19].

\section{Problem Statement}

Physical inactivity is considered nowadays "a major cause of morbidity and mortality, standing to show that physical inactivity is problematic." [8] Thus, "researchers and practitioners should search for PA programming options providing health benefits while featuring characteristics leading to sustained behavior. Interval training is an emerging trend with potential merits in this respect" [6].

Several researches "have suggested that a circuit training comprising endurance and resistance training may be preferred to one focusing only on a single exercise modality" [2], [16], [20].

"Both resistance training and aerobic training are advised for sedentary and obese people, given that they promote an improvement of blood pressure and heart rate, as well as body composition, biochemical markers such as insulin, glucose, cholesterol etc, and strength and aerobic capacity" [14], [7], [11].

The perks of circuit training are certainly "due to a stimulus on the enhancement of strength, hypertrophy, muscular endurance and aerobic capacity in one training session, capable of generating the anaerobic and 
aerobic workout benefits, though in to a lower extent compared to conventional methods" [4].

"Circuit training effectively mitigates the time dedicated to training while enabling an adequate training volume to be attained" [1]. Furthermore, it allows a greater motor engagement duration [9], which is an essential requirement for the training routine. "In addition, this methodology has multifold effects on fitness, mainly among beginners" [1], [5], [21].

A research conducted by Schmidt W. et al. [15] demonstrates that "a brief high intensity circuit training improves muscle endurance among moderately fit populations. Low improvements that are gender specific may also be noticed in muscle strength and in aerobic fitness" [15].

Furthermore, the findings of Miller's et al. pilot study are indeed promising. "They showed that a short duration High Intensity Circuit Training routine could have positive effects on several physiological health markers among obese males. Most improvements may be compared to those found in significantly longer duration High Intensity Circuit Training, resistance training, as well as aerobic exercise programs" [12].

\section{Research Questions/Aims of the research}

We have chosen to research this topic because the use of circuit training has great effects in the development of motor qualities, especially of strength and combined strength-resistance. The purpose of the paper was to select aerobic gymnastics exercises, to introduce them into circuits and to apply them within aerobic gymnastics sessions, and the results obtained to demonstrate their efficiency in the achieving of goals.

\section{Research Methods}

The sample comprised in the research included 15 women, who come to classes three times a week.

Methodology research

The study was conducted for eight months. The tests applied to the sample comprised in the research were the following: testing the strength and resistance of abdominal muscles (lying flat, legs on the floor, lift the torso to the perpendicular and come back); testing the strength of back muscles (lying face down, arms crossed behind the back, extend torso and come back); testing the strength of leg muscles (squats); testing the strength of arm muscles (push-ups). In all tests, we record the number of repetitions executed in 30 seconds.

As follows, we present 3 examples of circuits applied to the subjects included in the research. 
Circuit for beginner level (30" workout - 30" break)

The circuit is repeated 3 times with 1-minutes breaks between series. The total duration of the circuit training is approximately \pm 14 minutes.

Station 1: Lying down, arms at the sides: lift the torso at $45^{\circ}$ while taking the arms forward and return to the initial position; Station 2: Kick: I.P.: stand; jump on the right leg while swinging the left leg forward. The leg-lifting angle ranges between $90^{\circ}-170^{\circ}$. Repeat using the other leg. Station 3: Lying face down on floor, legs bent, hands at chest height: stretch the arms while lifting the hips up. Station 4: Lying face down on floor, arms stretched forward: lift both the torso and legs up; Station 5: I.P.: Standing legs apart, legs bent, hands on the hips: bend the torso leftwards while doing a left-leg half-lunge, take the right arm up and the left arm down and return to IP. Execute the same movement rightwards; Station 6: Jumping Jack + Knee.

Circuit for average level (45" workout - 30" break)

The circuit is repeated 2 times with 2 -minute breaks between series. The total duration of circuit training is approximately \pm 17 minutes.

Station 1: Lying down, arms at the sides: take the knees to the chest and return to the initial position; Station 2: 2 rightwards and leftwards lateral step-touch and 2 jumping-jacks with a $90^{\circ}$ turn leftwards and come back; Station 3: Lying face down on floor, arms stretched forward: lift the legs up and return to the initial position; Station 4: Standing legs apart, legs bent, arms bent in front of the chest: direct strikes (a movement specific to Tae Bo); Station 5: forward lunge + jumping jack; Station 6: Lying down, legs bent, soles on the floor, arms upwards: lift up the torso, touch the knees with the palms and return to the initial position.

Circuit for advanced level (50" workout - 30" break)

The circuit will be repeated 2 times with 2 -minute breaks between series. The total duration of circuit training is approximately \pm 18 minutes.

Station 1: knee + kick; Station 2: lying down, legs bent and soles on the floor, arms upwards: lift up the torso while outstretching the right/left leg and return to the initial position; Station 3: 2 forward lunge with the right/left leg +2 jumping-jack; Station 4: lying on the left side, left arm stretched forward, right hand behind the head: lift up the torso with support on the left hand and return to the initial position. Perform the same exercise on the opposite side; Station 5: lying face down on floor, legs lifted up and keeping the position, arms stretched forward: alternating leg raises; Station 6: lying down, legs stretched up, arms to the sides: lowering the legs to the side, to the right/left (as close to the floor as possible) and return to the initial position. 
Cristina-Elena MORARU et al. | Lumen Proceedings 9 | RSACVP2019

\section{Findings}

Table 1. Statistical indicators obtained in testing the strength and resistance of abdominal muscles

\begin{tabular}{lll}
\hline Statistical indicators & $\begin{array}{l}\text { I.T. } \\
\text { (No. of reps) }\end{array}$ & $\begin{array}{l}\text { F.T. } \\
\text { (No. of reps) }\end{array}$ \\
\hline Arithmetic mean & 13.8 & 15.2 \\
Standard deviation & \pm 1.52 & \pm 1.08 \\
Variability coefficient & $11.01 \%$ & $7.10 \%$ \\
\hline
\end{tabular}

Table 2. Statistical indicators obtained in testing the strength and resistance of back muscles

\begin{tabular}{lll}
\hline Statistical indicators & $\begin{array}{l}\text { I.T. } \\
\text { (No. of reps) }\end{array}$ & $\begin{array}{l}\text { F.T. } \\
\text { (No. of reps) }\end{array}$ \\
\hline Arithmetic mean & 21.46 & 23.53 \\
Standard deviation & \pm 1.684 & \pm 1.641 \\
Variability coefficient & $7.84 \%$ & $6.97 \%$ \\
\hline
\end{tabular}

Table 3. Statistical indicators obtained in testing the strength and resistance of lower limb muscles

\begin{tabular}{lll}
\hline Statistical indicators & $\begin{array}{l}\text { I.T. } \\
\text { (No. of reps) }\end{array}$ & $\begin{array}{l}\text { F.T. } \\
\text { (No. of reps) }\end{array}$ \\
\hline Arithmetic mean & 14.86 & 16.80 \\
Standard deviation & \pm 1.767 & \pm 1.473 \\
Variability coefficient & $11.89 \%$ & $8.76 \%$ \\
\hline
\end{tabular}

Table 4. Statistical indicators obtained in testing the strength and resistance of upper limb muscles

\begin{tabular}{lll}
\hline Statistical indicators & $\begin{array}{l}\text { I.T. } \\
\text { (No. of reps) }\end{array}$ & $\begin{array}{l}\text { F.T. } \\
\text { (No. of reps) }\end{array}$ \\
\hline Arithmetic mean & 14.40 & 16.26 \\
Standard deviation & \pm 0.985 & \pm 0.961 \\
Variability coefficient & $6.84 \%$ & $5.91 \%$ \\
\hline
\end{tabular}


Cristina-Elena MORARU et al. | Lumen Proceedings 9 | RSACVP2019

\section{Discussions}

The results of Sonchan's et al. research "suggest that the circuit training program improved muscle strength, agility, anaerobic capacity and cardiovascular endurance of the male students $(18.87+0.68 \mathrm{yr}$.) of the Faculty of Sport Science, Burapha University" [17].

"Four weeks of either one or two 6-min micro-sessions of multistimulating, circuit-like, multiple-joint training daily improves certain parameters of functional strength and certain dimensions of quality of life in untrained individuals. However, such exercise programs do not enhance cardio-respiratory fitness, having no effect in particular on peak oxygen uptake" [18].

The Mayorga's et al. research "suggests that it is possible to develop and maintain muscular and cardiovascular endurance through a short-term program in the physical education setting. Maintenance programs appear to be necessary in the school context to make the physical fitness training effective and feasible within a school plan, permitting at the same time the regular development of other curricular contents" [10].

\section{Literature review}

The Chtara's research "has shown that a 12-week, low-frequency, resistance-type circuit training program resulted in significant improvements in muscular strength, explosive strength and power, and strength endurance. Therefore, circuit type programs that use individualized intensities to ensure maximal effort over a short period are beneficial training strategies for improving overall strength. Second, when this training was combined with high-intensity endurance training, strength and explosive strength and power were still increased, but not to the same extent. Previous research had suggested that low-frequency endurance training does not compromise strength improvements, and, therefore, there is a possibility that highintensity interval training is more likely to be counter productive to strength and power adaptations when concurrent training is being performed. Last, the intrasession order of strength and endurance training resulted in no significant differences between these two conditions. This finding suggests that there is no advantage to performing either strength or endurance training before the other when both types of training are performed in a single session. However, if the development of strength and power is the priority of the program, then concurrent training in a single session is not advised" [3]. 


\section{Conclusions}

In the test for the strength and resistance of abdominal muscles, the values of the average and of standard deviation were $13.8 \pm 1.52$ initially and $15.2 \pm 1.08$ finally; concerning the strength and resistance of the back muscles, the values increased from $21.46 \pm 1.684$ initially to $23.53 \pm 1.641$ finally; in the strength and muscles of the legs, the values ranged between $14.86 \pm 1.767$ initially and $16.80 \pm 1.473$; in the strength and muscles of the arms, the values recorded an increase from $14.40 \pm 0.985$ initially to 16.26 \pm 0.961 finally. The present research demonstrated that the use of circuit workout can improve the motor qualities of strength and it can also improve the motor qualities of strength and resistance, which confirms the purpose of the paper.

Upon acquiring the circuit training, well rationalized, may be easily used in order to develop the motor qualities, being regulated by necessity, workout duration, breaks and number of executions.

\section{References}

[1] Alcaraz PE, Sánchez-Lorente J, Blazevich AJ. Physical performance and cardiovascular responses to an acute bout of heavy resistance circuit training versus traditional strength training. J Strength Cond Res. 2008 May; 22(3):667671.

[2] Bateman LA, Slentz CA, Willis LH, et al. Comparison of aerobic versus resistance exercise training effects on metabolic syndrome. Am J Cardiol. 2011 September 15; 108(6):838-844.

[3] Chtara M. Effect of concurrent endurance and circuit resistance training sequence on muscular strength and power development, Journal of Strength and Conditioning Research. 2008 July; 22(4):1037-1045.

[4] Contrò V, Bianco A, Cooper J, Sacco A, Macchiarella A, Traina M, Proia P. Effects of different circuit training protocols on body mass, fat mass and blood parameters in overweight adults. Journal of Biological Research. 2017 February 21; 90(1):6279:10-12.

[5] Dorgo S, King GA, Candelaria NG, Bader JO, Brickey GD, Adams CE. Effects of manual resistance training on fitness in adolescents. J Strength Cond Res. 2009; 23(8):2287-2294.

[6] Kilpatrick M, Jung M, Little JP. High-intensity interval training: A review of physiological and psychological responses. ACSM s Health \& Fitness Journal, 2014 September; 18(5):11-16.

[7] Kostrzewa-Nowak D, Nowak R, Jastrzębski Z, et al. Effect of 12-week-long aerobic training programme on body composition, aerobic capacity, complete 
blood count and blood lipid profile among young woman. Biochem Med (Zagreb) 2015 February 15; 25(1):103-113.

[8] Lollgen H, Bockenhoff A, Knapp G. Physical activity and all-cause mortality: an updated meta-analysis with different intensity categories. Int J Sports Med. 2009 March; 30(3):213-224.

[9] Lozano L, Viciana J, Martínez JC, Cocca A, Jiménez R. Influence of classroom environment and motor engagement time. Rev Mex Psicol. 2009; 26:675-676.

[10] Mayorga-Vega D, Viciana J, Cocca A. Effects of a Circuit Training Program on Muscular and Cardiovascular Endurance and their Maintenance in Schoolchildren. Journal of Human Kinetics. 2013 July; 37(1):153-160.

[11] Miller M., et al. The Effect of a Short-Term High-Intensity Circuit Training Program on Workout Capacity, Body Composition, and Blood Profiles in Sedentary Obese Men: A Pilot Study; Biomed Res Int. 2014 February 23:1-10.

[12] Miller MB, Pearcey GE, Cahill F, et al. The effect of a short-term highintensity circuit training program on workout capacity, body composition, and blood profiles in sedentary obese men: a pilot study. Biomed Res Int. 2014 February 23; 2014:191797.

[13] Paoli A, Bianco A, Neri M, Palma A. What is Fitness: definition, history and health benefits. A review. Iran J Public Health. 2015 May; 44(5):602-614.

[14] Regaieg S, Charfi N, Abid M. The effects of an exercise training program on body composition and aerobic capacity parameters in Tunisian obese children. Indian J Endocrinol Metab. 2013 December 3;17(6):1040-1045.

[15] Schmidt W, Anderson K, Graff M, Strutz V. The effect of high-intensity circuit training on physical fitness. J Sports Med Phys Fitness. 2016 May; 56(5):534-540.

[16] Slentz CA, Bateman LA, Willis LH, et al. Effects of aerobic vs. resistance training on visceral and liver fat stores, liver enzymes, and insulin resistance by HOMA in overweight adults (from STRRIDE AT/RT). Am J Physiol Endocrinol Metab. 2011 November; 301(5):1033-1039.

[17] Sonchan W, Moungmee P, Sootmongkol A. The Effects of a Circuit Training Program on Muscle Strength, Agility, Anaerobic Performance and Cardiovascular Endurance, World Academy of Science, Engineering and Technology, International Journal of Sport and Health Sciences. 2017; 11(4):176-179.

[18] Sperlich B. et al. A 4-Week Intervention Involving Mobile-Based Daily 6Minutes Micro-Sessions of Functional High-Intensity Circuit Training Improves Strength and Quality of Life, but Not Cardio-Respiratory Fitness of Young Untrained Adults. Frontiers in Physiology. 2018 May 9; 9:423.

[19] United States Department of Health and Human Services. Physical Activity Guidelines for Americans. Rockville (MD): Public Health Service; 2008: 7. 
Cristina-Elena MORARU et al. | Lumen Proceedings 9 | RSACVP2019

[20] Willis LH, Slentz CA, Bateman LA, et al. Effects of aerobic and/or resistance training on body mass and fat mass in over-weight or obese adults. J Appl Physiol. 2012 December 15; 113(12):1831-1837.

[21] Wong PCH, Chia MYH, Tsou IYY, Wansaicheong GKL, Tan B, Wang JCK, Tan J, Kim C, Boh G, Lim D. (2008). Effects of a 12-week exercise training programme on aerobic fitness, body composition, blood lipids and C-reactive protein in adolescents with obesity. Ann Acad Med Singapore. 2008 April; 37(4):286-293. 